\title{
Calibrating airborne measurements of airspeed, pressure and temperature using a Doppler laser air-motion sensor
}

\author{
W. A. Cooper, S. M. Spuler, M. Spowart, D. H. Lenschow, and R. B. Friesen \\ National Center for Atmospheric Research, Boulder CO, USA \\ Correspondence to: W. A. Cooper (cooperw@ucar.edu)
}

Received: 1 February 2014 - Published in Atmos. Meas. Tech. Discuss.: 14 March 2014

Revised: 12 August 2014 - Accepted: 25 August 2014 - Published: 30 September 2014

\begin{abstract}
A new laser air-motion sensor measures the true airspeed with a standard uncertainty of less than $0.1 \mathrm{~m} \mathrm{~s}^{-1}$ and so reduces uncertainty in the measured component of the relative wind along the longitudinal axis of the aircraft to about the same level. The calculated pressure expected from that airspeed at the inlet of a pitot tube then provides a basis for calibrating the measurements of dynamic and static pressure, reducing standard uncertainty in those measurements to less than $0.3 \mathrm{hPa}$ and the precision applicable to steady flight conditions to about $0.1 \mathrm{hPa}$. These improved measurements of pressure, combined with high-resolution measurements of geometric altitude from the global positioning system, then indicate (via integrations of the hydrostatic equation during climbs and descents) that the offset and uncertainty in temperature measurement for one research aircraft are $+0.3 \pm 0.3{ }^{\circ} \mathrm{C}$. For airspeed, pressure and temperature, these are significant reductions in uncertainty vs. those obtained from calibrations using standard techniques. Finally, it is shown that although the initial calibration of the measured static and dynamic pressures requires a measured temperature, once calibrated these measured pressures and the measurement of airspeed from the new laser air-motion sensor provide a measurement of temperature that does not depend on any other temperature sensor.
\end{abstract}

\section{Introduction}

Many of the core measurements made from research aircraft are interconnected. To measure temperature, corrections must be made for dynamic heating caused by the motion of the aircraft; to measure airspeed, measurements of dynamic pressure, ambient pressure and temperature are needed; corrections are often made to the measured pressure that depend on the airspeed and/or orientation of the aircraft; accurate measurement of airspeed depends on knowing the humidity of the air and so the appropriate gas constants and specific heats; measurements of humidity by dew-point sensors must be corrected for differences between ambient and sensor pressures; etc. There are seldom standards or reliable references for any of these, so uncertainty analyses involve complicated and multi-dimensional examinations of these interactions and of how flight conditions might influence measurements from otherwise carefully calibrated sensors.

If one could obtain a reliable reference for any of these interlinked measurements, it could be of great value in reducing measurement uncertainty. A new instrument, a Laser Air Motion Sensor (LAMS), now provides such a reference on the National Science Foundation/National Center for Atmospheric Research (NSF/NCAR) Gulfstream GV and C-130 research aircraft (hereafter referred to as the GV and C-130). This paper explores how measurements from this instrument can reduce measurement uncertainties in some key measurements made on those aircraft. The new sensor is compact and designed to be installed inside standard instrument canisters, so the measurements and approach taken here can be extended readily to most other research aircraft.

Gracey (1980) reviewed calibration techniques that have been used to calibrate measurements of pressure. The following are examples, including some developed after that review:

1. The trailing cone. This is usually considered the best standard. A stainless steel tube with inlets around its circumference is trailed so as to be aligned with its long axis along the airflow. A cone is attached to the end of the line to keep it aligned along the airflow, and 
the tube is trailed behind the aircraft at a distance and vertical displacement sufficient to be outside airflow effects of the aircraft. The inlets are connected by tubing to sensors inside the aircraft, and the measurement so obtained is compared to that from the sensors being calibrated. Ikhtiari and Marth (1964), Haering Jr. (1995) and many others have described this system. It can be used while the aircraft airspeed, altitude and attitude angles are changed through the normal flight envelope. The disadvantages are that the system usually requires a special and difficult installation, which can be particularly problematic for a pressurized aircraft flying at low pressure, and the trailing cone is not suitable for routine measurement. When available, though, it provides accurate calibration; Brown (1988) obtained a pressure calibration of a high-speed aircraft with standard uncertainty of about $0.2 \mathrm{hPa}$, in ideal conditions, using a trailing cone. (Throughout this paper, quoted uncertainties are standard uncertainties corresponding to one standard deviation.)

2. Intercomparisons. Research aircraft are often flown in formation to collect measurements that identify differences. There are many published examples, but most identify differences outside the claimed error limits and seldom are able to determine which measurement is at fault.

3. Flights past towers. Flights past high towers or tethered balloon sensors can provide limited checks on the accuracy of measured pressures, but these are only possible at low altitude and low airspeed so are not suited to calibration of an aircraft like the GV.

4. Calibration by the global positioning system (GPS) where the wind is known. If the wind is known accurately by independent measurement, the drift measured by GPS can be compared to the drift expected in the wind measured by the aircraft, and the associated dynamic pressure can be corrected to minimize the difference from the independent measurement of wind. Examples are discussed by Foster and Cunningham (2010) and by Martos et al. (2011), where dynamic pressure was calibrated by comparing wind measured on the aircraft to that measured from a tethered balloon. GPS measurements have also been used without an independent reference, with flight manoeuvres and Kalman filtering, to calibrate dynamic pressure (Cho et al., 2011).

5. Use of measurements at ports around a sphere. Rodi and Leon (2012) showed that multiple measurements of pressure at ports on the surface of a sphere can be used to determine the error in measured ambient pressure and, when combined with GPS measurements, can lead to corrections for errors introduced by accelerated motion of the aircraft.
The analysis that follows demonstrates that the LAMS provides another means of calibrating pressure to a level of uncertainty competitive with the best of the aforementioned techniques while providing calibrations that can be available for routine use. The operating principles of the LAMS are discussed in the next section. The absolute measurement of airspeed that the LAMS provides makes it possible to deduce the expected dynamic pressure (or the pressure increase above ambient or "static" pressure that occurs when air is brought to a stagnation point in flight) with reduced uncertainty. It will be argued that this measured correction to the dynamic pressure can then be used to improve measurements of the ambient pressure. Once pressure is known with small uncertainty, temperature differences can be determined during altitude changes by integration of the hydrostatic equation between flight levels because the geometric altitudes of the bounding flight levels are also known with small uncertainty from recent improvements in measurements from the global positioning system. Finally, it is shown that the LAMS provides a direct measurement of temperature that is independent of conventional temperature sensors. This measurement should be valid during cloud penetrations as well as in clear air. The conclusions of the paper then will summarize how this analysis has reduced measurement uncertainty for key state-parameter measurements from these research aircraft.

\section{The NCAR laser air-motion sensor}

The laser air-motion sensor (LAMS) used in this study is that described by Spuler et al. (2011). Figure 1 shows the general layout of this instrument on the GV. It is a focused, continuous-wave, coherent Doppler laser remote sensing system based on general principles described by Sonnenschein and Horrigan (1971). In essence, these instruments transmit a frequency-stable continuous-wave laser beam and receive the light backscattered from aerosols present in the atmosphere in a weighted distribution around where the beam is focused. If the scattering aerosols have a velocity along the radial path of the beam, the received backscattered light is Doppler shifted. The received laser light is mixed with a portion of the transmitted laser light via optical heterodyning, in which the coherent wavefronts of the transmitted and received beams interfere constructively and destructively at a frequency that is proportional to the transmitted laser wavelength and the wind speed along the line of sight of the laser.

This particular instrument is a single-beam system in which a laser is focused ahead of the aircraft in undisturbed air so that the airspeed can be measured outside the disturbed airflow caused by the aircraft. Different configurations were used in this study for the GV and C-130. In both cases, the instrument was mounted under the wing and was aligned about $3^{\circ}$ downward relative to the aircraft centre line to compensate for the normal angle of attack. For the GV, the focus 


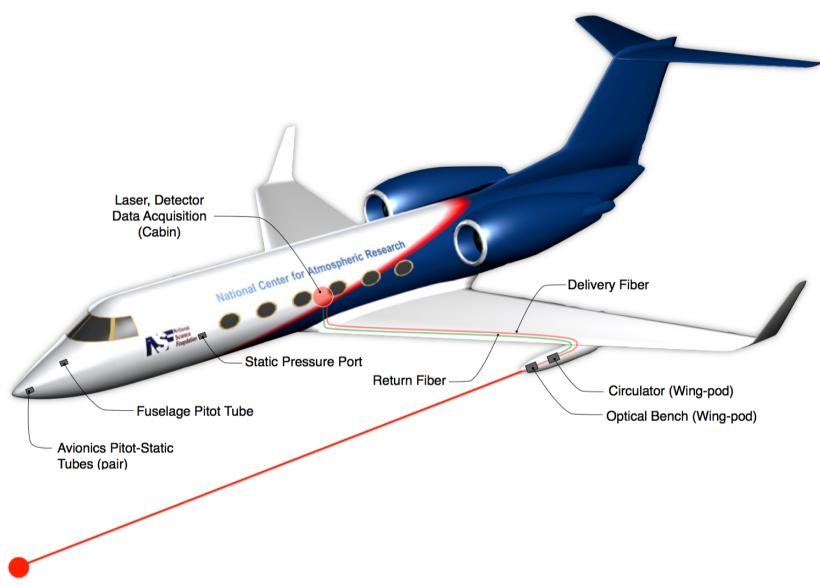

Figure 1. Diagram of the LAMS. Light generated by the laser in the cabin is transmitted by optical fibres to a wing pod, where it is transmitted in a beam that has a focal point well ahead of the aircraft (farther ahead than suggested by this not-to-scale diagram). The light backscattered from aerosol particles in the focal region is collected by the lens, and a circulator mixes a portion of the transmitted signal with the returned signal. The resulting signal, with interference patterns that measure the Doppler shift of the backscattered light, is returned via optical fibre to the cabin for digitization. Also illustrated in this figure are the approximate locations of the static pressure ports and the fuselage pitot tube used by the research data system to measure static and dynamic pressures. This figure appears in Applied Optics in the article by Spuler et al. (2011) and is used here with permission from the Optical Society of America.

was $30 \mathrm{~m}$ ahead of the instrument, or $16 \mathrm{~m}$ ahead of the nose of the aircraft. For the C-130, the focal distance was $15 \mathrm{~m}$ ahead of the instrument. Different lens $f$ numbers were used, such that in both cases the returned signal was dominantly from a volume extending about $2.5 \mathrm{~m}$ along the direction of flight, as given by the full-width half-maximum distance of the telescope gain pattern. A small inertial system (Systron Donner C-MIGITS INS/GPS) mounted in the wing pod with the LAMS measured deviations in orientation caused by wing flex or other vibrations of the pod relative to the aircraft centre axis, where the aircraft orientation was measured by a separate Honeywell Laseref IV or V SM inertial reference system. Both provided measurements of attitude angles and aircraft velocity with respective standard uncertainties of about $1 \mathrm{mrad}$ and about $0.1 \mathrm{~m} \mathrm{~s}^{-1}$, after incorporation of measurements from global positioning system (GPS) receivers.

Earlier versions of laser wind sensors operating at $10.6 \mu \mathrm{m}$ wavelength were designed for use on NCAR aircraft in the 1980s and 1990s, as discussed by Keeler et al. (1987), Kristensen and Lenschow (1987) and Mayor et al. (1997), but developments in fibre optics now have made a much improved system practical. For the present system, the wavelength used is about $1.56 \mu \mathrm{m}$; Spuler et al. (2011) estimated that a particle concentration of about $2 \mathrm{~cm}^{-3}$ with a diameter in the range from 0.1 to $3 \mu \mathrm{m}$ is needed to provide a detectable signal, but the sensitivity has been improved since that early test. Successful detection of the backscattered signal has been possible at altitudes extending to above $13 \mathrm{~km}$ although with present sensitivity there are still times when the signal is too small for a valid measurement.

The precision estimated in Spuler et al. (2011) is $0.05 \mathrm{~m} \mathrm{~s}^{-1}$ for $1 \mathrm{~s}$ samples (as will be used in the present analyses); however, the system can provide data at much higher rates because individual samples are recorded at $100 \mathrm{~Hz}$ after the averaging of individual spectra sampled at rates of about $200 \mathrm{kHz}$. The light source is a distributed feedback fibre laser module (NKT Basik E15) with wavelength $1559.996 \mathrm{~nm}$ in vacuum and $0.1 \mathrm{pm}\left({ }^{\circ} \mathrm{C}\right)^{-1}$ stability. The laser is maintained within $1^{\circ} \mathrm{C}$ of a constant temperature, so wavelength drift is below $0.001 \mathrm{~nm}$. The conversion from measured Doppler shift to airspeed involves only the wavelength of the laser and the speed of light. The error attributed to variation in the laser wavelength is equivalent to $0.01 \mathrm{~mm} \mathrm{~s}^{-1}$ for wind measurements that are typically about $200 \mathrm{~m} \mathrm{~s}^{-1}$. In comparison to the overall $50 \mathrm{~mm} \mathrm{~s}^{-1}$ precision of the measurement, this error makes a negligible contribution to precision or uncertainty.

The peak Doppler frequency can be measured with a standard uncertainty that, converted to airspeed, is less than $0.1 \mathrm{~m} \mathrm{~s}^{-1}$. The precision estimate from Spuler et al. (2011) also supports an estimated uncertainty in this range if there is no bias in the selection of the peak in the shifted frequency spectrum, as is supported by careful examination of the recorded spectra and the operation of the algorithm that identifies the peak (discussed at the end of Sect. 3 of that reference). When the signal-to-noise ratio indicates that there is inadequate signal from which to obtain a Doppler shift, the measurements are flagged as missing and are not used in the analysis to follow.

\section{Calibrating the pressure-sensing system}

\subsection{Dynamic pressure}

The most straightforward application of measurements from the LAMS is to predict the dynamic pressure $q$. If $p$ is the ambient pressure, $c_{v}$ and $c_{p}$ the respective specific heats of air at constant volume or constant pressure, $T$ the absolute temperature, and $R_{\mathrm{a}}$ the gas constant for air, the Mach number $M$ (ratio of flight speed $v$ to the speed of sound $\sqrt{\gamma R_{\mathrm{a}} T}$, with $\gamma=c_{p} / c_{v}$ ) is given by the following equation (cf. e.g. Lenschow, 1972):

$M=\frac{v}{\sqrt{\gamma R_{\mathrm{a}} T}}=\left\{\left(\frac{2 c_{v}}{R_{\mathrm{a}}}\right)\left[\left(\frac{p+q}{p}\right)^{R_{\mathrm{a}} / c_{p}}-1\right]\right\}^{1 / 2}$. 
Solving for the dynamic pressure gives

$q=p\left\{\left(\frac{v^{2}}{2 c_{p} T}+1\right)^{c_{p} / R_{\mathrm{a}}}-1\right\}$,

which shows that, with knowledge of $p$ and $T$, LAMS (measuring $v$ ) can provide an independent prediction of the dynamic pressure $q$. Furthermore, small errors in $p$ and $T$ will have a small effect on the deduced dynamic pressure because expected errors are a small fraction of the total ambient pressure or the absolute temperature. For typical flight conditions, an uncertainty in temperature of $1 \mathrm{~K}$ leads to a fractional uncertainty in $q$ of about $0.5 \%$ or, for $q=60 \mathrm{hPa}$, about $0.3 \mathrm{hPa}$. Because the calibration of the temperature sensors is tested in Sect. 5 of this paper to a standard uncertainty of $0.3^{\circ} \mathrm{C}$, this uncertainty in temperature leads to an uncertainty in calibrated dynamic pressure of about $0.1 \mathrm{hPa}$.

Corrections are usually applied to measurements of dynamic pressure on research aircraft, including the NSF/NCAR research aircraft, so comparing $q$ as provided by Eq. (2) to the uncorrected measurement of dynamic pressure $q_{\mathrm{m}}$ is an exaggeration of the improvement that LAMS provides. Nevertheless, Fig. 2 shows that the difference between the predicted value from LAMS using Eq. (2) and the direct measurement (from one of the pitot tubes on the C-130 referenced to the static pressure source) is substantial and exhibits both a large bias and significant scatter. Applying corrections to the direct measurement is therefore important if the air motion relative to the aircraft is to be determined accurately.

\subsection{Ambient or static pressure}

The normal measurement of total pressure $p_{\mathrm{t}}=p+q$ is obtained on the GV and C-130 and many other research aircraft by measuring the pressure delivered by a pitot tube aligned approximately along the airflow. This measurement is made by adding two measurements, one of ambient pressure $p$ (measured by a Parascientific Model 1000 absolute pressure transducer with $0.1 \mathrm{hPa}$ measurement uncertainty, connected in parallel to static ports on each side of the fuselage of the aircraft) and a second of dynamic pressure $q$ (measured by a Honeywell PPT (0-5 PSI) differential sensor with $0.02 \mathrm{hPa}$ measurement uncertainty, connected between the static ports and the pitot tube). These measurements are sampled at $50 \mathrm{~Hz}$, filtered to $25 \mathrm{~Hz}$ and optionally averaged to $1 \mathrm{~Hz}$. Two independent systems with separate static ports are available on the $\mathrm{C}-130$, but only one on the GV. On both aircraft, there are also measurements from another independent system that supplies information to the flight crew and is also recorded for research use.

Pitot tubes are generally insensitive to small deviations from normal flow angles, typically delivering accurate total pressure within about $0.1 \%$ for flow angles up to several degrees from the centreline of the pitot tube (e.g. Gracey et al., 1951; Balachandran, 2006; Tropez et al., 2007). However,

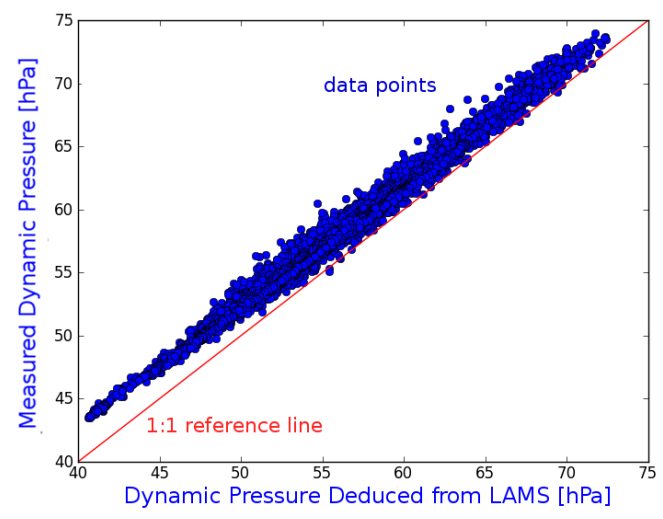

Figure 2. The direct measurement of dynamic pressure $\left(q_{\mathrm{m}}\right)$ on the C-130 vs. that deduced using the LAMS measurement of airspeed, via Eqs. (3) and (5). All $1 \mathrm{~s}$ average points from one C-130 research flight on which the LAMS was tested (17 November 2011) are shown.

static ports can deliver pressures that depart much more from the true ambient pressure at the flight level when flow around the fuselage varies, and they can also produce biases even at normal flight angles, so the largest error is expected in $p$ and consequently in $q$ while their sum $p_{\mathrm{t}}$ has a substantially smaller error. This was checked on the GV and on the C130 by comparing the redundant sources for these measurements. The results for $p_{\mathrm{t}}$ were remarkably consistent among all pairs (agreeing to within $0.1 \mathrm{hPa}$ ) but there was significant variability in the redundant measurements of both $p$ and $q$, often at the level of a few hPa.

For example, Fig. 3 compares two redundant measurements of total pressure on the C-130, each based on a different pitot source and static source. This and other similar comparisons suggest that a good approximation is to consider $p_{\mathrm{t}}$ accurately measured and to assume that $\Delta q$, the error in the measurement $q_{\mathrm{m}}$ of dynamic pressure, is equal to the negative of $\Delta p$, the error in the measurement $p_{\mathrm{m}}$ of ambient pressure, because both arise from the "static defect" or error in the pressure present at the static source:

$\Delta q=q_{\mathrm{m}}-q=-\Delta p=-\left(p_{\mathrm{m}}-p\right)$.

As a result, the correction to dynamic pressure obtained from LAMS also provides a correction to ambient pressure, and these corrections can be applied simultaneously in Eq. (3) using Eq. (2):

$\Delta q=q_{\mathrm{m}}-p \chi(v, T)$,

where, to simplify the notation, $\chi(v, T)$ is

$\chi(v, T)=\left(\frac{v^{2}}{2 c_{p} T}+1\right)^{c_{p} / R_{\mathrm{a}}}-1$.

Then, because $p=p_{\mathrm{m}}-\Delta p$,

$p_{\mathrm{c}}=-\Delta p=\frac{q_{\mathrm{m}}-p_{\mathrm{m}} \chi}{1+\chi}$ 


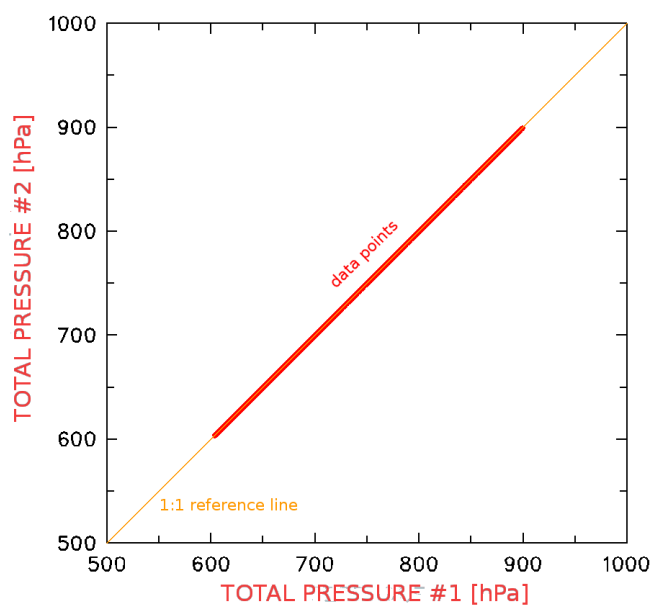

Figure 3. Measurements made at $1 \mathrm{~Hz}$ during the 17 November 2011 flight of the C-130. All measurements are included for times when the true airspeed exceeded $50 \mathrm{~m} \mathrm{~s}^{-1}$ (to exclude a short period with flaps deployed at the end of the flight). The measurements plotted are the total pressure $p_{\mathrm{t}}$, measured by two independent systems using two different pitot tubes and sets of static buttons. The root-mean-square deviation from this line is $0.1 \mathrm{hPa}$, and the similar deviation from a best-fit line is less than $0.04 \mathrm{hPa}$

which gives the correction to ambient pressure $p_{\mathrm{c}}$ in terms of the measurements of ambient and dynamic pressure, the airspeed measured by the LAMS and the absolute temperature. The negative sign arises because the correction needed is the negative of the measurement error.

The temperature is needed to calculate $\chi$, but it can be assumed tentatively that the uncertainty in the temperature measurement is adequate for this analysis. Once pressure corrections are found, this assumption can be checked and the process can be iterated as necessary. Equations (4) and (5) then can be used with measurements from the LAMS to estimate both the correction to be applied to the ambient pressure and, with reversed sign, the correction to be applied to the dynamic pressure.

The results obtained in this way are dependent on the specific locations of the pressure ports providing the static source. Haering Jr. (1995) discusses general considerations regarding placement and characteristics of these ports. On the research aircraft discussed in the present paper, to avoid interference with the standard ports used by the avionics systems, separate ports have been installed to provide this static source. The locations on the GV, shown in Fig. 1, are at fuselage station 247.0 and water line 80.2 (by convention quoted in inches, equal to 6.274 and $2.032 \mathrm{~m}$ respectively), symmetrically on the starboard and port sides. The primary pitot tube on the $\mathrm{GV}$ is located at fuselage station $54.0(1.572 \mathrm{~m})$ and butt line $-19.0(-0.483 \mathrm{~m}$, negative indicating on the port side). The correction procedure developed in Sect. 3.5 depends on measurements of flow angle as determined by pressure measurements from the radome gust system (with pressure ports on the nose of the aircraft), so the pitot tube needs to be relatively close to the nose in order for those measurements to provide accurate characterization of flow conditions in turbulent conditions. Other locations for the static sources will have different errors and different dependence on flow characteristics. This approach to calibration, however, should work with any pitot source that is insensitive to flow angles and is installed outside the boundary layer of the fuselage.

\subsection{Some refinements}

The goal of these analyses is to measure state variables with significantly lower uncertainty than has been possible in the past, so this objective requires attention to some minor error sources. Specifically, it was necessary to consider: (i) the humidity of the air and its effect on thermodynamic properties like the gas constant and specific heats; (ii) the effect of small departures of the pointing angle of the LAMS beam from the direction of the relative wind and (iii) possible effects of flow angles on the total pressure measured by the pitot tube.

\subsubsection{Correction for humidity}

The first was determined in a straightforward way by considering the properties determined from weighted averages of the properties of dry air and humid air, in standard ways, as described by Khelif et al. (1999). Many of the preceding equations are affected by these adjustments to the gas constant and specific heat for moist air.

\subsubsection{Correction for LAMS orientation}

Although a pitot tube is relatively insensitive to flow angles and so measures the total dynamic pressure, LAMS measures only a projected component of the relative wind, so a correction for the difference between its orientation and that of the relative wind is needed. Because there was an inertial reference system mounted on the same under-wing pylon that carried the LAMS, it was possible to correct for small departures in pointing angle relative to the aircraft reference line, the orientation of which was also measured by a separate inertial reference system. These two inertial systems align independently with uncertainties of about $1 \mathrm{mrad}$, and the attack and side-slip angles $\alpha$ and $\beta$ are measured using the method of Brown et al. (1981), so the flow angles relative to the LAMS beam are $\theta_{1}+\alpha$ and $\theta_{2}-\beta$, where $\theta_{1}$ and $\theta_{2}$ are respectively the angles of the LAMS beam above and to the starboard side of the aircraft axis, as measured by the differences in pitch and heading from the two inertial systems. The needed correction is determined by the angle $\theta$ specified, to a sufficient approximation, by $\cos \theta=\cos \left(\theta_{1}+\alpha\right) \cos \left(\theta_{2}-\beta\right)$. The resulting equations for the pressure correction are then Eqs. (4) and (5) where, in Eq. (4), $v$ is replaced by $v_{l} / \cos \theta$. However, because typical values of $\theta$ were about $1^{\circ}$ and $\cos \left(1^{\circ}\right) \simeq 0.9998$, these corrections were usually quite small. 


\subsubsection{Effect of flow not parallel to the pitot tube}

According to information provided by manufacturers, the typical sensitivity of a pitot tube to flow direction is less than $1 \%$ at flow angles up to $10^{\circ}$ and less than $0.2 \%$ for flow angles up to $5^{\circ}$. See also the general discussion in Haering Jr. (1995). The error is in the direction of measuring too low a total pressure as the flow angle increases, and to some extent it is compensated by orienting the pitot tubes along the average flow direction expected in normal flight.

To check this, a flight segment with LAMS operational included yaw manoeuvres in which the aircraft was flown in conditions of small side-slip $\left(<3^{\circ}\right)$ in cross-controlled conditions so that the aircraft continued in approximately the same direction and at approximately the same airspeed. Under those conditions, one would expect that the total pressure measured by the pitot tube would not show a dependence on side-slip angle.

Because a low-tolerance test is desired, small corrections are needed for the observed departures from steady flight speed and in altitude. Over the course of the manoeuvre, GPS measurements of altitude were used with the hydrostatic equation to estimate and correct for changes in the ambient pressure using $\delta p=-\left(p / R_{\mathrm{a}} T\right) g \delta z$, where $\delta z$ is the change in altitude from the start of the flight segment, $p$ is the ambient pressure, $R_{\mathrm{a}}$ the gas constant for air, $T$ the absolute temperature and $g$ the acceleration of gravity. In addition, a correction was made for the expected change in total pressure arising from small changes in airspeed, as measured by the LAMS. This is an independent measurement of airspeed that does not rely on the aircraft measurements of ambient and dynamic pressure, so the correction is not affected by possible errors in the measurement of dynamic pressure. The correction applied is given by the following equation:

$\delta q=\left(\frac{p}{R_{\mathrm{a}} T}\left(\frac{v^{2}}{2 c_{p} T}+1\right)^{\frac{c_{p}}{R_{\mathrm{a}}}-1} v\right) \delta v$,

which is obtained by differentiating Eq. (2). In this equation, $v$ is the airspeed measured by LAMS (corrected for flow angles as specified above) and the increment is referenced to the arbitrary starting value in the time series so that corrections are made for the non-steady flight speed during the manoeuvres.

With these corrections, the average total pressure measurements as a function of the magnitude of the side-slip angle are as shown in Fig. 4. Within a limit of about $0.1 \mathrm{hPa}$, there is no dependence on side-slip angle out to about $3^{\circ}$, a range in side-slip angles and also in attack angles from the mean that is characteristic of normal flight of both NCAR aircraft. This supports neglecting a possible dependence of the total pressure measurement on flow angles, at least for the small angles characteristic of normal flight; however, the test is not as rigorous as might be desired because airflow distortion around

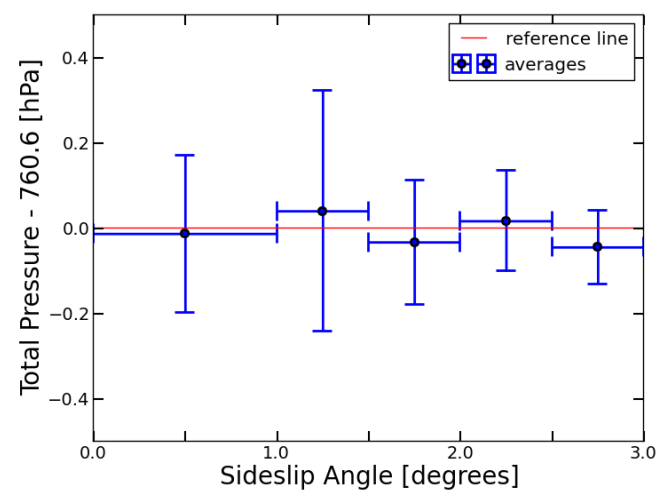

Figure 4. The total pressure (from the sum of the ambient pressure measurement and the dynamic pressure measurement) on the C-130 as a function of the magnitude of the side-slip angle during yaw manoeuvres in which side-slip angles were forced by rudder action while the aircraft continued on approximately a straight-and-level course. The mean total pressure of $760.6 \mathrm{hPa}$ has been subtracted from the measurements. Error bars are standard deviations in the measurements for the total pressure axis and are the range of the bin used in side-slip. Corrections for deviations from a level course and for small variations in airspeed have been applied, as discussed in the text.

the fuselage may cause the flow angle at the pitot tube to differ from the measured side-slip angle.

\subsection{Uncertainty in the corrections}

When the LAMS is operating, the corrections to ambient and dynamic pressure can be determined directly from Eqs. (3) and (5), and these corrections have much stronger justification than the empirical corrections used previously. The LAMS evaluation (Spuler et al., 2011) suggests that the uncertainty in line-of-sight $v$ is about $0.05 \mathrm{~m} \mathrm{~s}^{-1}$, so this is also approximately the uncertainty in the component of the relative wind along the axis of LAMS. The total derivative of Eq. (2) provides a basis for evaluating the uncertainty in the value of $q$ estimated from Eq. (2):

$$
\frac{\delta q}{p}=\left(\frac{v^{2}}{2 c_{p} T}+1\right)^{\frac{c_{p}}{R_{\mathrm{a}}}-1} \frac{v^{2}}{R_{\mathrm{a}} T}\left(\frac{\delta v}{v}-\frac{1}{2} \frac{\Delta T}{T}\right) .
$$

The temperature uncertainty thus contributes significantly to the uncertainty in $q$, often more than the uncertainty in $v$ from LAMS, because $\delta v / v \approx 0.05 / 220 \approx 0.00023$ while for temperature, an uncertainty of $0.3{ }^{\circ} \mathrm{C}$ results in a larger fractional contribution of $0.5 \times 0.3 / 223 \approx 0.00067$ (for the GV). To reduce the uncertainty in temperature used in Eq. (2), the airspeed from LAMS can be used directly in the correction for dynamic heating, avoiding uncertainty in the conventional airspeed arising from error in measured dynamic pressure. That is, the temperature should be determined directly from 
$T=T_{\mathrm{r}}-\alpha_{T} \frac{v^{2}}{2 c_{p}}$,

with $T_{\mathrm{r}}$ the measured or "recovery" temperature, $\alpha_{T}$ the recovery factor for the sensor measuring $T_{\mathrm{r}}$, and $v$ provided by LAMS rather than the conventional solution for the Mach number determined from ambient and dynamic pressure. The recovery factor used for the GV in this study (specified later, in Sect. 5.2) was determined by fitting to data in Stickney et al. (1994), where reported measurements span a range in $a_{T}$ that corresponds to a standard uncertainty of about 0.007 in $\alpha_{T}$. For a representative airspeed of $220 \mathrm{~m} \mathrm{~s}^{-1}$ this corresponds to an uncertainty in temperature of about $0.2^{\circ} \mathrm{C}$. Calibration of the temperature measurement, which includes dependence on the recovery factor, is presented in Sect. 5.2, where it is argued that the temperature is constrained by that calibration within about $0.3^{\circ} \mathrm{C}$ of that measured, so using $v$ as measured by LAMS keeps the standard uncertainty introduced by $T$ within this limit.

Interpreted as an uncertainty in dynamic pressure $q$, the uncertainty in the prediction of $q$ from LAMS determined from Eq. (7) is typically about $0.13 \mathrm{hPa}$ (for flight at $125 \mathrm{~m} \mathrm{~s}^{-1}$, where the pressure is $760 \mathrm{hPa}$ and the temperature $0^{\circ} \mathrm{C}$ ). The uncertainty in the uncorrected measurement of $p_{\mathrm{m}}$, from instrument characteristics, is also about $0.1 \mathrm{hPa}$, so using the LAMS correction yields an ambient pressure that has an uncertainty of around $0.16 \mathrm{hPa}$. Evaluation at $150 \mathrm{hPa}$ leads to a similar estimate of uncertainty. When LAMS is present, it is thus possible to be confident that the measurements of the longitudinal component of the relative wind and of the ambient pressure have associated standard uncertainties of $<0.1 \mathrm{~m} \mathrm{~s}^{-1}$ and $0.16 \mathrm{hPa}$, respectively.

\subsection{Fits to the corrections}

There is still value in determining fits to the corrections provided by LAMS in terms of flight characteristics like flight level, angle of attack, Mach number etc. because then corrections can be applied in cases where the LAMS is not present or does not detect enough signal to provide a valid airspeed. Such fits can be applied retrospectively to data collected before the LAMS was available, and the fits can also be compared to other means of estimating the corrections. A further reason for developing fits is that the LAMS measurement, being offset from the nose of the aircraft, represents a region where there may be a fluctuating difference in airspeed vs. that present at the nose, and averaging over such fluctuations as provided by functional fits smooths the predicted corrections. Fits to the measurements may therefore be preferable to those corrected directly using the LAMS airspeed $v$, especially in turbulent regions. For these reasons, fits to the measurements provided by Eq. (5) were explored until adequate representations of the predicted fits were found. Variables considered in the fits included ambient pressure, dynamic pressure, Mach number, angle of attack, side-slip, airspeed and other characteristics of flight. The following analyses use flights during which the LAMS provided valid measurements almost continuously and during which there were many altitude changes and speed variations.

\subsubsection{GV}

For the GV, the best representation of $\Delta p$, obtained after trying many options, was

$$
\begin{aligned}
\frac{\Delta p}{p} & =a_{0}+a_{1} M^{2}+a_{2} M^{3}+a_{3} \frac{\Delta p_{\alpha}}{\Delta q_{\mathrm{r}}} \\
& +a_{4}\left(\frac{\Delta p_{\alpha}}{\Delta q_{\mathrm{r}}}\right)^{2}+a_{5}\left(\frac{\Delta p_{\alpha}}{\Delta q_{\mathrm{r}}}\right)^{3},
\end{aligned}
$$

where $\Delta p_{\alpha}$ is the pressure difference between vertically separated pressure ports on the radome (normally used to calculate the angle of attack; cf. Brown et al., 1983) and $\Delta q_{\mathrm{r}}$ is the pressure difference measured between the centre port on the radome and the static source. The terms involving $\Delta p_{\alpha} / \Delta q_{\mathrm{r}}$ introduce dependence on angle of attack. The dimensionless coefficients $\left\{a_{0}, a_{1}, a_{2}, a_{3}, a_{4}, a_{5}\right\}$ for the best fit to the measurements from a GV flight with LAMS operating were, respectively, $\{-0.0133,0.0425,-0.0716,-0.360,-3.60,-9.66\}$, where the quoted significant digits reflect the standard error in determining these coefficients. In the analysis of significance of the fit, all these coefficients were needed to represent the variance, at significance levels less than 0.001 .

The correlation coefficient between the measured pressure corrections and those predicted by Eq. (9) was 0.98 and the standard error was 0.00089 (i.e. $0.089 \%$ of the measured pressure, or about $0.3 \mathrm{hPa}$ at a typical ambient pressure of $p=350 \mathrm{hPa}$ ). This standard error reflects individual measurements for which some scatter arises because the LAMS and pressure-sensing systems detect air parcels slightly displaced from each other that potentially have different air motions (cf. the discussion of this point in Sect. 4). The high correlation coefficient indicates that the fit accounts for $>96 \%$ of the variance between the predicted and measured pressure corrections. Including additional functional dependence terms in Eq. (9) did not reduce the residual variance beyond this limit, so there is no evident source of this residual variability beyond the fraction that may arise from the samples being at different locations for the two systems.

The LAMS measurements indicate that, for this set of flight conditions, the ambient pressure should be corrected by $3.5 \mathrm{hPa}$ and the standard deviation in that correction is $1.45 \mathrm{hPa}$. If Eq. (9) accounts for $96 \%$ of that variance, the remaining variance is equivalent to a residual standard deviation of $<0.3 \mathrm{hPa}$. Because most of that variance arises from turbulent regions where the volumes sampled by the LAMS and the pressure-sensing system could be moving differently, this can be interpreted as an upper limit to the uncertainty 
in the pressure correction. Thus, using the LAMS measurement of airspeed has removed a $3.5 \mathrm{hPa}$ error and provided a reference for a parametric fit that has residual uncertainty of $<0.3 \mathrm{hPa}$. Any random error in the uncorrected measurement of pressure would appear in this residual uncertainty, as would a random error in the LAMS measurement, and a bias in the measurement of pressure would be corrected by the calibration procedure. Bias in the LAMS measurement of airspeed of, e.g. $0.05 \mathrm{~m} \mathrm{~s}^{-1}$ would still lead to a bias in the calibrated pressure of typically about $0.15 \mathrm{hPa}$, as argued in Sect. 3.4, but this is still small in comparison to the residual uncertainty arising from the parametrized fit.

A concern regarding Eq. (9) is that during the flight from which this fit was determined the variable $\Delta p_{\alpha} / \Delta q_{\mathrm{r}}$ varied only from about -0.2 to -0.03 , while the full flight envelope of the GV spans a larger range. There is a danger that the cubic dependence on this term in Eq. (9) might extrapolate to erroneous corrections outside that range. To guard against such errors, other fits were developed that, although slightly less accurate, should extrapolate to new conditions better. One example is the following:

$$
\frac{\Delta p}{p}=a_{0}^{\prime}+a_{1}^{\prime} \frac{q_{\mathrm{m}}}{p_{\mathrm{m}}}+a_{2}^{\prime} M^{3}+a_{3}^{\prime} \frac{\Delta p_{\alpha}}{\Delta q_{\mathrm{r}}},
$$

with values of the coefficients $\left\{a_{i, i=0-3}^{\prime}\right\}$ respectively $\{-0.00076,0.073,-0.0864,0.0465\}$. The resulting correction is plotted in Fig. 5, for flight at $500 \mathrm{hPa}$. This fit to the LAMS measurements accounted for $95 \%$ of the variance, vs. $96 \%$ for Eq. (9), so it may be preferable to use Eq. (10) in cases where flight conditions might fall outside the normal range of angle of attack used to determine Eq. (9).

\subsubsection{C-130}

Fits to the values of Eq. (5) obtained as above were also explored for a C-130 flight with LAMS operating. For one pair of measurements of ambient pressure and dynamic pressure, the best fit with all highly significant coefficients (significance level $<0.001$ ) was the following:

$$
\frac{\Delta p}{p}=b_{0}+b_{1} \frac{\Delta p_{\alpha}}{\Delta q_{\mathrm{r}}}+b_{2} M+b_{3} \frac{\Delta p_{\beta}}{\Delta q_{\mathrm{r}}}
$$

where $\Delta p_{\beta}$ is analogous to $\Delta p_{\alpha}$ but for the side-slip angle. The standard error for this fit was 0.0004 , corresponding to a pressure uncertainty at $700 \mathrm{hPa}$ of about $0.3 \mathrm{hPa}$ for the individual measurements. The second term gave the largest reduction in residual error; using this variation alone gave a residual standard error of 0.00050 . A fit using only the first three terms on the right side of Eq. (11) increased the residual standard error by less than 0.00001 , making an additional error contribution to the corrected pressure of typically $0.014 \mathrm{hPa}$, which is insignificant in comparison to other expected error sources, so this simpler fit may be preferable. The coefficients, with quoted significant digits determined with consideration the standard errors in the fit, are

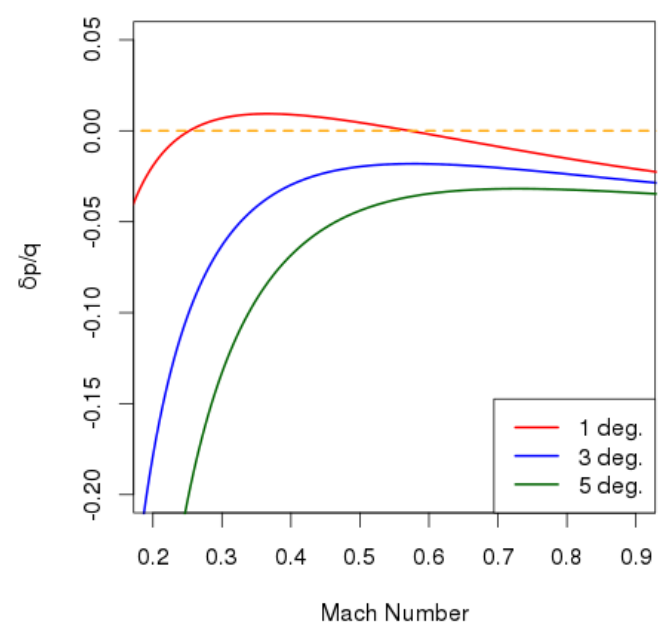

Figure 5. The correction to pressure $(\delta p)$ normalized by the magnitude of the dynamic pressure $(q)$, as a function of Mach number, for three values of the angle of attack. The values plotted are those for the GV as given by Eq. (9) for flight at $500 \mathrm{hPa}$. The format of the plot is chosen to match conventional presentations in aeronautical publications such as Gracey (1980).

$\left\{b_{0}^{\prime}, b_{1}^{\prime}, b_{2}^{\prime}\right\}=\{0.00152,0.0205,0.0149\}$. While the residuals from this fit are small, the mean offset it produces is about $2 \mathrm{hPa}$, so (as illustrated by Fig. 2) the effect on the measurements of ambient and dynamic pressure is quite significant.

For both aircraft, direct use of the LAMS measurements can reduce the uncertainty in measurements of ambient and dynamic pressure to around $0.15 \mathrm{hPa}$. Even when the LAMS is not present, parametric fits to LAMS measurements can reduce the uncertainty in pressure to less than $0.3 \mathrm{hPa}$.

\subsection{Comparisons to other evidence}

There are several comparisons possible that can test these results. Three are discussed in this section.

\subsubsection{Wind measurements in reverse-heading manoeuvres}

A reverse-heading manoeuvre is one in which a straight-andlevel flight leg is flown for a short time ( 2 to $5 \mathrm{~min}$ ) and then the aircraft reverses course and flies the same leg in the opposite direction. Usually these are flown approximately along and against the wind direction. A test of the accuracy of the measurement of dynamic pressure is that the longitudinal component of the wind should reverse direction but have the same magnitude in reverse-heading manoeuvres when the aircraft is flown over the same (drifting) flight leg twice with opposite headings. To isolate the effect of the measurement of $q$ and hence true airspeed, the best wind component to use is that along the axis of the aircraft, which is $v_{\mathrm{g}} \cos \delta-v_{\mathrm{t}}$, where $v_{\mathrm{g}}$ is the ground speed of the aircraft, $v_{\mathrm{t}}$ the true airspeed relative to the air and $\delta$ is the angle between the ground-speed vector and the heading of the aircraft. The 
GPS system provides the ground-speed magnitude $v_{\mathrm{g}}$ and the ground track angle $\Phi$, so $\delta=\Phi-\Psi$, where $\Psi$ is the heading of the aircraft. Then, the wind component along the longitudinal axis of the aircraft is

$v_{x}=v_{\mathrm{g}} \cos (\Phi-\Psi)-v_{\mathrm{t}}$,

where $v_{\mathrm{t}}$ is provided either directly from LAMS or from the corrected dynamic pressure via Eq. (9) for the GV or Eq. (11) for the $\mathrm{C}-130$. The expectation is that the longitudinal component of the wind given by Eq. (12) will reverse sign between the two legs of the reverse-heading manoeuvre. Within statistics imposed by atmospheric fluctuations, this is then a test of the validity of the longitudinal component of the wind measurements.

A GV flight with a large number of reverse-heading manoeuvres, but without the LAMS, was used for the test described in this section. Table 1 shows the results for 12 reverse-heading pairs of legs from this flight. The mean difference on legs along opposing headings was $-0.12 \pm$ $0.91 \mathrm{~m} \mathrm{~s}^{-1}$, but there are two pairs of legs (marked with asterisks in the table) that appear to be outliers such as would be expected if the wind conditions changed between the two legs. If these are excluded, the remainder give a standard deviation such that the excluded legs would be more than two standard deviations from the mean. Excluding these two legs, there are 10 legs with a mean difference of $-0.26 \pm$ $0.43 \mathrm{~m} \mathrm{~s}^{-1}$, with standard error in the mean of $0.14 \mathrm{~m} \mathrm{~s}^{-1}$. This result suggests that the error in measurement of longitudinal wind is $-0.13 \pm 0.07 \mathrm{~m} \mathrm{~s}^{-1}$, which is consistent with estimates of the uncertainty associated with the applied correction to airspeed based on Eq. (10). This provides supporting evidence that the standard uncertainty in the measurement of the longitudinal component of the relative wind after correction is about $0.1 \mathrm{~m} \mathrm{~s}^{-1}$.

\subsubsection{The avionics pressure system of the GV}

The ambient pressure measurement from the avionics system on the GV is more reliable than those on many research aircraft because the GV is certified to fly on RVSM (reduced vertical separation minimum) levels; therefore, the flightdeck pressure measurement has met strict Federal Aviation Administration requirements. Appendix G to Federal Aviation Regulations Part 91 specifies that the maximum allowable error in altitude is $80 \mathrm{ft}$, or about $24 \mathrm{~m}$. In the RVSM altitude range (flight levels 290 to 410), this corresponds to a requirement that the error in pressure be in the range of about $0.68 \mathrm{hPa}$ (near FL410) to $1.1 \mathrm{hPa}$ (near FL290). For the GV flight used above, the mean difference between the pressure provided by the avionics system and that measured with correction by LAMS, for the RVSM altitude range, was $+0.36 \mathrm{hPa}$ with standard deviation $0.19 \mathrm{hPa}$, so within the tolerance required by RVSM standards, the avionics pressure is consistent with the measured pressure as calibrated in this study.

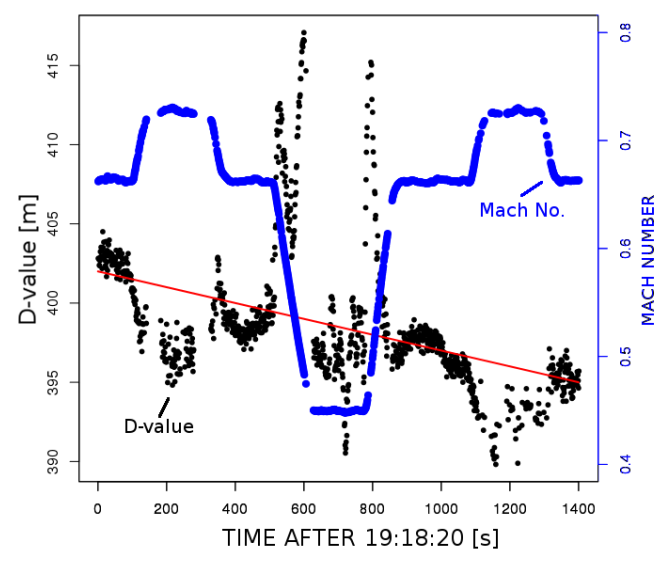

Figure 6. The $d$ value measurements as a function of time for a flight segment at about $450 \mathrm{hPa}$, and the corresponding values of the Mach number (plotted relative to the right axis). It might be expected that the $d$ value would change smoothly, as suggested by the solid red line. GV flight of 12 August 2010, Colorado, USA to St. Croix, Virgin Islands. Gaps in data show portions omitted because the LAMS signal was too weak to be reliable.

\subsection{3 " $d$ value" measurements during speed runs}

The dominant dependence in the pressure correction represented in Eq. (9) is on Mach number, so testing this dependence is a useful constraint on the validity of the corrections. Repeatedly during the flight used to determine the pressure calibration in this study, the GV was flown in level flight, moving from near its low-speed limit to near its highspeed limit. If the pressure corrections are adequate, such manoeuvres should not introduce perturbations into the measured pressure. A stringent test of this expected independence of Mach number is to consider the difference between the geometric altitude and the pressure altitude, or " $d$ value" (cf. Bellamy, 1945) during the manoeuvre. This compensates for small altitude changes of the aircraft and should show a continuous change not perturbed by the airspeed changes or small altitude changes.

When the aircraft, at about $450 \mathrm{hPa}$ flight altitude, was slowed to its minimum speed of about Mach 0.45, there was a clear perturbation in the $d$ value plot during the transitions from Mach 0.67 to Mach 0.73 and back, as shown in Fig. 6. However, during the flight segments at steady speed the various measurements of $d$ value are consistent to within about $3 \mathrm{~m}$, a change in $d$ value corresponding to a pressure change of only about $0.2 \mathrm{hPa}$. In the higher Mach number range of the flight envelope, deviations were still smaller, consistent with linear change with time to within about $0.1 \mathrm{hPa}$. This is an indication that the larger deviations of the fit from the LAMS-measured values occur at the extremes of the flight envelope, and that errors in the corrections represented by Eq. (9) are reduced if the aircraft remains close to its normal flight envelope in unaccelerated flight. However, the 
Table 1. Pairs of reverse-heading manoeuvres. Average values for altitude, heading and the longitudinal component of the wind $\left(v_{x}\right)$ are listed. Data from the GV flight of 6 August 2010.

\begin{tabular}{lrrrr}
\hline Time (UTC) & Altitude $(\mathrm{m})$ & Heading & $v_{x}\left(\mathrm{~m} \mathrm{~s}^{-1}\right)$ & $\Delta v_{x}$ \\
\hline 17:38:45-17:39:45* & 8835 & 240 & -12.305 & \\
17:42:30-17:43:30* & 8832 & 57 & 14.678 & 2.373 \\
17:46:30-17:47:30 & 10060 & 240 & -23.930 & \\
17:50:30-17:51:30 & 10070 & 57 & 23.433 & -0.497 \\
17:55:00-17:56:00 & 10980 & 241 & -18.904 & \\
17:59:00-18:00:00 & 10980 & 57 & 18.520 & -0.384 \\
18:03:00-18:04:00 & 11900 & 240 & -26.330 & \\
18:07:15-18:08:15 & 11900 & 57 & 26.309 & 0.022 \\
18:17:00-18:19:00 & 12830 & 59 & 19.993 & \\
18:28:00-18:30:00 & 12820 & 239 & -19.542 & 0.451 \\
18:31:00-18:33:00* & 12810 & 239 & -19.948 & \\
18:36:15-18:38:15* & 12810 & 59 & 18.823 & -1.125 \\
18:45:00-18:47:00 & 12810 & 239 & -19.294 & -0.471 \\
18:48:00-18:50:00 & 12800 & 240 & -19.477 & \\
18:53:00-18:55:00 & 12800 & 59 & 18.711 & -0.766 \\
18:54:00-18:56:00 & 12800 & 59 & 19.015 & \\
19:01:30-19:03:30 & 12800 & 239 & -19.147 & -0.131 \\
19:20:00-19:22:00 & 4227 & 10 & 1.522 & \\
19:27:00-19:29:00 & 4228 & 190 & -1.827 & -0.305 \\
19:28:00-19:30:00 & 4228 & 189 & -1.341 & \\
19:33:00-19:35:00 & 4242 & 10 & 1.678 & 0.337 \\
19:41:00-19:43:00 & 4242 & 190 & -2.542 & -0.864 \\
\hline MEAN & & & & -0.113 \\
\hline MEAN excluding two anomalous pairs marked by asterisks & & & & -0.261 \\
\hline
\end{tabular}

consistency of the trend suggests that the dependence of the correction on Mach number is appropriate to within an uncertainty of about $0.2 \mathrm{hPa}$.

\section{Correcting the measured airspeed}

The LAMS provides a direct measurement of line-of-sight airspeed and, with the correction as in Sect. 3.3.2, true airspeed, but it is still useful to use the pressures as determined in the preceding section to determine airspeed by solving Eq. (2) for $v$ as a function of $p$ and $q$. Because the volume in which LAMS senses the airspeed is displaced from the nose of the aircraft, the airspeed that it senses may differ slightly from that sensed at the radome of the aircraft. For the GV, the difference between the airspeed measured by LAMS and that determined from the corrected dynamic and ambient pressures has a standard deviation of $0.35 \mathrm{~m} \mathrm{~s}^{-1}$. Estimates based on measured turbulence levels indicate that this is similar to the difference expected for sample locations separated by about $16 \mathrm{~m}$, the distance between the LAMS sensing volume and the nose of the GV, but for this comparison the samples are $1 \mathrm{~s}$ averages that would be expected to differ by much less than this, perhaps reduced by a factor of around $\sqrt{200 / 16}$. This suggests that differences in location account for perhaps $30 \%$ of the observed standard deviation. This fraction is still significant, so even when the LAMS is present, airspeed used to determine the wind may be better if based on the corrected pressures that use the parametric fits rather than that measured directly by the LAMS.

On the GV, the mean change in true airspeed introduced by this calibration is $-0.8 \mathrm{~m} \mathrm{~s}^{-1}$. The standard error in the determination of this offset is much smaller than the expected uncertainty in the measurement from LAMS (which is $<0.1 \mathrm{~m} \mathrm{~s}^{-1}$ ), so calibration using LAMS has removed $\mathrm{a}-0.8 \mathrm{~m} \mathrm{~s}^{-1}$ error and reduced the uncertainty in this measurement to $<0.1 \mathrm{~m} \mathrm{~s}^{-1}$. For the $\mathrm{C}-130$, the corresponding correction is $+0.5 \mathrm{~m} \mathrm{~s}^{-1}$. These measurements are used along with measurements from GPS and an inertial reference system (IRS) to determine the wind, and the GPS/IRS also provides measurements with an uncertainty of about $0.1 \mathrm{~m} \mathrm{~s}^{-1}$, so the calibration based on LAMS has reduced the uncertainty in the component of the wind along the aircraft axis to $<0.2 \mathrm{~m} \mathrm{~s}^{-1}$.

\section{Checking the calibrations of thermometers}

With accurate measurements of both pressure and geometric altitude, it is possible to test calibrations of the temperature 
sensors on the research aircraft by calculating height differences from integration of the hydrostatic equation and comparing them to measured height differences. The latter are provided with low uncertainty by modern GPS measurements of geometric altitude. The improved measurement of pressure provided by LAMS reduces the uncertainty in the measurement of pressure differences and enables a more stringent test of the validity of the measurements of temperature.

The hydrostatic equation can be expressed in this form:

$\delta p_{i}=-\frac{g p_{i}}{R_{\mathrm{a}} T_{i}} \delta z_{i}$,

where $\left\{p_{i}, T_{i}\right\}$ are the values of ambient pressure and absolute temperature for the $i$ th measurement and $\delta p_{i}$ is the change in pressure for the $i$ th step, during which the geometric altitude changes by $\delta z_{i}$. This equation can be rearranged to obtain an estimate of the temperature:

$T_{i}=-\frac{g}{R_{\mathrm{a}}} \frac{\delta z_{i}}{\delta \ln p_{i}}$.

Measurement uncertainty of $0.1 \%$ in derived temperature (i.e. a typical uncertainty of $0.3^{\circ} \mathrm{C}$ ) requires at least $0.1 \%$ precision in the measurement of $\delta z$, a precision now provided by differential GPS receivers (such as the NovAtel Model OEM-4 L1/L2 Differential GPS system in use on both NCAR aircraft) for height differences as small as $100 \mathrm{~m}$. The requirement is more stringent for the measurement of pressure. At $10 \mathrm{~m} \mathrm{~s}^{-1}$ rate of climb, the pressure change over $10 \mathrm{~s}$ is less than $10 \mathrm{hPa}$, and it seems likely that differences in pressure cannot be measured confidently to better than $0.1 \mathrm{hPa}$, so this would introduce an error of $1 \%$ in the deduced (absolute) temperature. This is inadequate, so a larger altitude difference or the average of many measurements is required to obtain a useful estimate of the temperature.

\section{$5.1 \quad C-130$}

About 30 min of flight with the LAMS on the C-130 was devoted to repeated climbs and descents and included about 1800 measurements of $1 \mathrm{~s}$ differences, so it might be expected that the standard error in the determination of temperature from Eq. (14) could be reduced by $\sqrt{1800}=42$, or to around $0.5^{\circ} \mathrm{C}$, by this procedure. Alternately, an appropriately weighted "mean" temperature between two levels can be determined from Eq. (14). For this flight segment, climbs were repeated from about 12000 to $16000 \mathrm{ft}$ (about 3.7 to $4.9 \mathrm{~km}$ ), or over a pressure range of about $100 \mathrm{hPa}$, and the course reversed midway through the flight segment, so this should help compensate for any true horizontal gradient in pressure. An uncertainty of $0.1 \mathrm{hPa}$ in a $100 \mathrm{hPa}$ pressure change leads to about an uncertainty of $0.1 \%$ or, in absolute temperature, an uncertainty of about $0.3^{\circ} \mathrm{C}$ in the mean temperature between the layers. It should therefore be possible to test the temperature measurements with about this level of confidence.

Specifically, three sums were calculated between different flight levels:

$$
\begin{aligned}
& S_{1}=\sum_{i} \frac{R_{\mathrm{a}, i}}{g_{i}} \ln \left(\frac{p_{i}}{p_{i-1}}\right), \\
& S_{2}=\sum_{i}\left(z_{i}-z_{i-1}\right), \\
& S_{3}=\sum_{i} \frac{z_{i}-z_{i-1}}{T_{\mathrm{m}, i}},
\end{aligned}
$$

where $R_{\mathrm{a}, i}$ and $g_{i}$ are respectively the gas constant (adjusted for humidity) and the acceleration of gravity (adjusted for latitude and altitude) and $T_{\mathrm{m}, i}$ is the measured temperature in absolute units, corrected for airspeed but based on the standard sensors being tested. The predicted mean temperature for the layer, weighted by altitude, is given by $T_{\mathrm{p}}=-S_{2} / S_{1}$, while the corresponding weighted-mean measured temperature is $\bar{T}_{\mathrm{m}}=S_{2} / S_{3}$, so a comparison of $\bar{T}_{\mathrm{m}}$ to $T_{\mathrm{p}}$ tests the validity of the temperature measurement.

Table 2 shows some measurements from selected flight legs of the $\mathrm{C}-130$. The evidence from these climbs indicates that the measured temperature was about $0.5^{\circ} \mathrm{C}$ too high and that the offset perhaps increases as the temperature decreases. After this result was obtained, an investigation discovered an error of about this magnitude in the calibration of the temperature sensor, which arose from a flawed bath calibration. This illustrates the value of the independent calibration provided by the LAMS.

\subsection{GV}

A similar approach could be taken for the GV, with the promise of a larger range of calibration points because of the large altitude changes occurring during many of the flights. However, because there have been many flights with frequent altitude changes, it was decided instead to use a large data set with many climbs and descents to determine a polynomial correction to the temperature via minimization of the error between actual altitude changes and those predicted from integration of the hydrostatic equation. The chi-square $\left(\chi^{2}\right)$ to be minimized was

$\chi^{2}=\sum_{i} \frac{1}{\sigma_{z}^{2}}\left(h_{i}-Z_{i}\right)^{2}$,

where $Z_{i}$ is the geometric altitude measured by GPS, $\sigma_{z}$ is the uncertainty in the height measurement and the predicted height $h_{i}$ was determined by the integration of the hydrostatic equation in the form

$$
\begin{aligned}
& h_{i}=h_{i-1}-\frac{R_{\mathrm{a}}\left(f\left(T_{i}\right)\right)}{g} \ln \frac{p_{i}}{p_{i-1}}, \\
& f\left(T_{i}\right)=\frac{\left(c_{0}+\left(1+c_{1}\right) T_{i}+T_{0}\right)}{1+\alpha_{T} \frac{R_{\mathrm{a}}}{2 C_{v}} M^{2}},
\end{aligned}
$$


Table 2. Comparisons of predicted and measured temperatures from climbs and descents of the C-130. The segments are from flights RF05, RF06 and RF08 flown respectively on 7, 15 and 17 November 2011. $T_{\mathrm{p}}$ is the predicted temperature and $\bar{T}_{\mathrm{m}}$ is the weighted mean of the measured values of temperature, as defined in the text.

\begin{tabular}{lrrr}
\hline Flight number, times UTC & $T_{\mathrm{p}}\left[{ }^{\circ} \mathrm{C}\right]$ & $\bar{T}_{\mathrm{m}}\left[{ }^{\circ} \mathrm{C}\right]$ & $T_{\mathrm{p}}-\bar{T}_{\mathrm{m}}$ \\
\hline RF05, 20:58:00-21:11:00 & -10.98 & -10.37 & -0.5 \\
RF07, 21:25:10-21:33:00 & -6.36 & -5.89 & -0.47 \\
RF07, 21:25:10-21:29:00 & 2.27 & 2.42 & -0.15 \\
RF07, 21:29:00-21:33:00 & -12.85 & -12.15 & -0.70 \\
RF08, 21:45:00-21:53:00 & -0.9 & -0.5 & -0.4 \\
RF08, 23:37:00-23:41:30 & -6.5 & -6.3 & -0.4 \\
RF08, 23:45:00-23:50:00 & -9.4 & -8.8 & -0.6 \\
RF08, 23:56:00-24:01:00 & -9.5 & -8.4 & -1.1 \\
\hline mean offset, $T_{\mathrm{p}}-\bar{T}_{\mathrm{m}}$ & & & -0.55 \\
\hline
\end{tabular}

where $c_{0}$ and $c_{1}$ are coefficients to be found by minimization of Eq. (18). In these equations, $R_{\mathrm{a}}$ is the moist-air gas constant, $g$ the acceleration of gravity (adjusted for latitude and altitude) and $\left\{p_{i}\right\}$ is the time sequence of measured pressures. The function $f\left(T_{i}\right)$ allows the adjustable coefficients $c_{0}$ and $c_{1}$ to be applied to the measured temperature $T_{i}$, with conversion to ambient temperature on the basis of the recovery factor $\left(\alpha_{T}\right)$, the Mach number $(M)$ and the specific heat at constant volume $\left(c_{v}\right)$. The resulting temperature is converted to an absolute temperature by the addition of $T_{0}=273.15 \mathrm{~K}$.

Because the climbs and descents were made en route and so spanned some horizontal distance, the vertical integration will match the pressure change only if the atmosphere is horizontally homogeneous. If not, the results will be biased as the fit attempts to compensate for horizontal gradients, and this can introduce an error into the minimization results. To consider how serious this problem is, it is useful to assess how a pressure gradient will affect the results. Suppose the horizontal pressure gradient along the flight path is $\mathrm{d} p / \mathrm{d} s=G_{p}$. Then, there will be a contribution to the pressure change arising just from the pressure gradient over a period $\Delta t$, of magnitude $G_{p} v \Delta t$, where $v$ is the airspeed. Therefore, in Eq. (19) the pressure ratio in the logarithmic factor must be modified to be $\left(p_{i}-G_{p} v_{i} \Delta t\right) / p_{i-1}$.

It is convenient to express this in terms of $d$ value, the difference between geometric altitude and pressure altitude, because that is measured routinely. Part of the change in $d$ value during a climb results from the horizontal pressure gradient, while another part arises from the climb in an atmosphere that differs from the standard atmosphere. The expected change in $d_{i}$, the measurement of $d$ value, is then

$$
\begin{aligned}
d_{i}-d_{i-1} & =-\left(\frac{R_{\mathrm{a}} f\left(T_{i}\right)}{g}-\frac{R_{\mathrm{S}} T_{\mathrm{S}}(p)}{g_{\mathrm{S}}}\right) \ln \frac{p_{i}}{p_{i-1}} \\
& -\frac{G_{p} R_{\mathrm{a}} T_{i} v_{i} \Delta t}{g p_{i}}
\end{aligned}
$$

where $R_{\mathrm{S}}$ and $g_{\mathrm{s}}$ are the gas constant and acceleration of gravity defined by the US standard atmosphere and $T_{\mathrm{S}}(p)$ is the absolute temperature corresponding in the standard atmosphere to pressure $p$. The first term on the right side arises from the climb or descent, while the last term is the contribution from the horizontal pressure gradient. The horizontal pressure gradient $G_{p}$ can then be deduced from the measurements of $d$ value by rearranging Eq. (21):

$$
\begin{aligned}
G_{p} v_{i} \Delta t & =\frac{g p_{i}}{R_{\mathrm{a}} T_{i}} \times \\
& \left\{-\left(\frac{R_{\mathrm{a}} f\left(T_{i}\right)}{g}-\frac{R_{\mathrm{s}} T_{\mathrm{s}}\left(p_{i}\right)}{g_{\mathrm{s}}}\right) \ln \frac{p_{i}}{p_{i-1}}\right. \\
& \left.-\left(d_{i}-d_{i-1}\right)\right\} .
\end{aligned}
$$

Then, the altitude-change equation, Eq. (19), should be replaced by

$h_{i}=h_{i-1}-\frac{R_{\mathrm{a}}\left(f\left(T_{i}\right)\right)}{g} \ln \left(\frac{p_{i}-G_{p} v_{i} \Delta t}{p_{i-1}}\right)$,

with $G_{p} v_{i} \Delta t$ evaluated using Eq. (22).

The measurements used were from 10 flights that comprised the fifth circuit of the High-performance Instrumented Airborne Platform for Environmental Research (HIAPER) Pole-to-Pole (HIPPO) experiment (Wofsy et al., 2011), starting and ending in Colorado, USA, but extending north of the Arctic Circle and south to beyond New Zealand. The flight patterns featured repeated climbs and descents to measure profiles through the atmosphere, so the 122 profiles measured (many covering more than $8 \mathrm{~km}$ in altitude) provided a good set of measurements for this study. Several data-quality restrictions were applied to avoid periods of problematic data, notably when ice accumulation or frozen water affected the wind-sensing system and so the measurement of attack angle (needed for the correction to ambient pressure). Periods with climb or descent rates less than $2 \mathrm{~m} \mathrm{~s}^{-1}$ were excluded as a way of excluding level flight segments that contributed noise to the analysis. Also, rare periods of climbs or descents exceeding $7.5 \mathrm{~m} \mathrm{~s}^{-1}$ were also excluded because those periods produced large discrepancies in the results compared to normal climbs and descents, perhaps because of problems with sensor response. Flight periods with airspeed less than $130 \mathrm{~m} \mathrm{~s}^{-1}$ were also excluded to avoid times when the flaps might have been deployed, potentially affecting the pressure measurements. With these exclusions, the data set consisted of about 26000 samples during climbs and descents.

For measurements made at a rate of $1 \mathrm{~Hz}$, the uncertainty $\sigma_{z}$ in measurement of the height difference arises primarily from the uncertainty in the pressure change, as discussed above. The best-fit value of $\chi^{2}$ as defined by Eq. (18) was consistent with a value of about $1.6 \mathrm{~m}$ for $\sigma_{z}$, and this would be appropriate if the uncertainty in pressure (at a representative altitude of about 300 to $500 \mathrm{hPa}$ ) were about $0.1 \mathrm{hPa}$, 
so this uncertainty in altitude is consistent with other estimates in this paper. The minimization was done in various ways, including evaluating results over matrices of values of the fit parameters $c_{0}$ and $c_{1}$, conjugate-gradient stepping and use of the "R" routine optim (R Core Team, 2013) which implements the Nelder and Mead (1965) minimization algorithm. All produced consistent results, with convergence to values of $\left\{c_{0}, c_{1}\right\}=\left\{0.32{ }^{\circ} \mathrm{C}, 0.007\right\}$. This adjustment from the measurements would change the measured total temperature over the course of these flights by $+0.29 \pm 0.13 \mathrm{~K}$, so the fit indicates that the error in the measured temperature is within these limits. This result applies to the measurement of total temperature, but the minimization of Eq. (18) depended on the accuracy of the ambient temperature after application of the recovery factor (using $\alpha_{T}=$ $0.988+0.053 \log _{10} M+0.090 \log _{10} M^{2}+0.091 \log _{10} M^{3}$, obtained as explained in Sect. 3.4), so the constraint on measurement uncertainty tests for errors in the recovery factor as well as the calibration of the temperature sensor and digitization system.

The uncertainty in the determination of the fit parameters $\left\{c_{0}, c_{1}\right\}$ is about $\{0.02,0.001\}$, but the uncertainty matrix is highly correlated such that the range of values giving an increase in $\chi^{2}$ equal to the mean contribution from each point spans from $\{0.030,0.006\}$ to $\{0.034,0.008\}$. Within this range, the mean change in temperature implied by the fit remains in the range 0.28 to $0.31 \mathrm{~K}$ and the standard deviation in the correction remains smaller than $0.15 \mathrm{~K}$, so there is low uncertainty in the implied adjustment needed for temperature.

A potentially more significant source of error, however, is the effect of measurements that for some reason are questionable or erroneous. As discussed above, such measurements were excluded where they were identified, but some may remain. To check on the effects of variations in the measurements entering the minimization, the sequence of measurements was split into five segments and fit coefficients were determined for each. The means of these fit coefficients were $\{0.37,0.018\}$ and when used individually to evaluate the adjustment needed in the full data set, these fits indicated an adjustment of $0.30 \pm 0.30$. These estimates of uncertainty then indicate a required adjustment in temperature of about $+0.3 \pm 0.3{ }^{\circ} \mathrm{C}$, with the adjusted total absolute temperature $T^{\prime}$ given in relation to measured total temperature $T$ by $T^{\prime}=T_{0}+c_{0}+\left(1+c_{1}\right)\left(T-T_{0}\right)$, where $c_{0}=0.32^{\circ} \mathrm{C}$ and $c_{1}=0.007$. This estimated correction and associated uncertainty, obtained because the LAMS provides a calibration of the pressure-sensing system and so with GPS enables accurate integration of the hydrostatic equation, are obtained independent of reference standards or intercomparisons with other sensors and are the best available estimate of uncertainty in the temperature measurement from the GV.

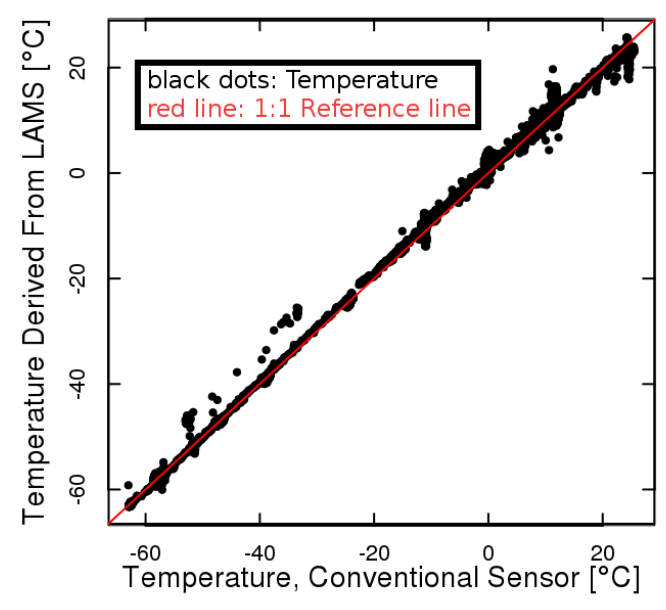

Figure 7. Temperature determined from LAMS using Eq. (24) plotted as a function of the corresponding direct measurement of temperature for the ferry flight from Colorado, USA to St. Croix, Virgin Islands, on 10 August 2010. Each plotted point represents a measurement representing $1 \mathrm{~s}$ of flight.

\section{Using the LAMS to measure temperature}

As discussed above, the LAMS provides a measurement of the true airspeed $v$ and also enables corrections that improve the measurements of the ambient and dynamic pressure. Those two pressures are sufficient to determine the Mach number $M=v / v_{\mathrm{s}}$, where $v_{\mathrm{s}}=\sqrt{\gamma R_{\mathrm{a}} T}$ is the speed of sound in air. An equation for temperature can be obtained from Eq. (2) rewritten in the form

$$
T=\frac{v^{2}}{2 c_{p}\left[\left(\frac{p_{\mathrm{t}}}{p}\right)^{R_{\mathrm{a}} / c_{p}}-1\right]} .
$$

Once calibrated, measurements of $p$ and $p_{\mathrm{t}}$ thus can be combined with $v$ from LAMS to determine the temperature without any further reference to temperature sensors on the aircraft.

Figure 7 shows the measurements obtained using Eq. (24) in comparison to the primary conventional measurement of temperature. The mean difference (LAMS temperature minus conventional temperature) is $0.02{ }^{\circ} \mathrm{C}$ and the standard deviation is $1.1^{\circ} \mathrm{C}$. The fairly large standard deviation arises mostly from areas of significant turbulence. A histogram of the difference shows that the central peak is characterized by a standard deviation of about $0.5^{\circ} \mathrm{C}$ and extremes account for the increase to $1.1^{\circ} \mathrm{C}$ in the full sample.

Figure 8 shows a comparison of the temperature determined from the LAMS and that measured directly during a portion of a flight of the C-130. The variance is significantly higher in the LAMS-determined temperature for the flight segment in the boundary layer (near 2100Z). This may arise in part because the flow conditions at the pitot tube and in the air sampled by LAMS can be different. Measured airspeeds 

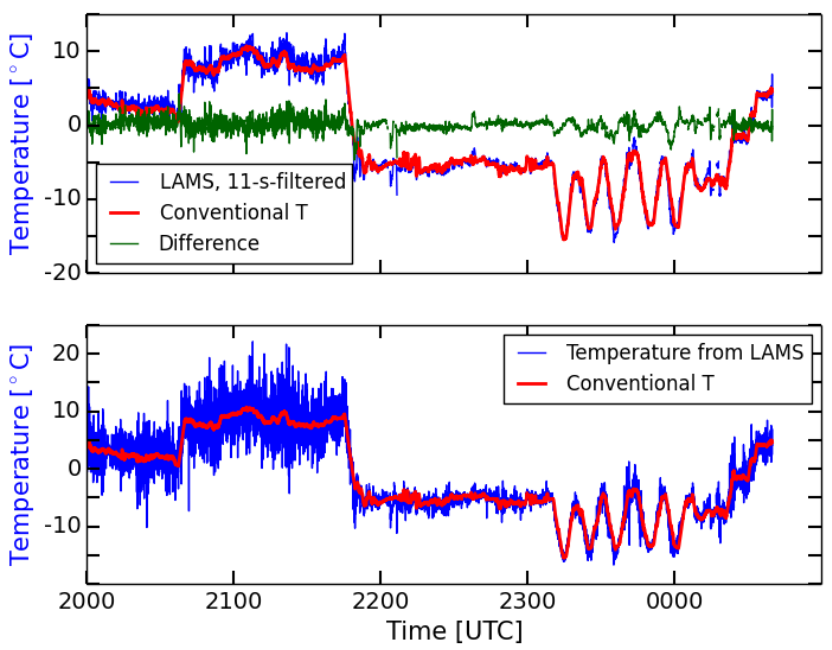

Figure 8. Temperature determined from LAMS plotted with the standard measurement of temperature for a flight segment from the C-130 flight of 17 November 2011, and the difference between the two measurements. The bottom panel shows the $1 \mathrm{~Hz}$ measurements from LAMS; in the top panel, these have been smoothed by an $11 \mathrm{~s}$ box average.

from the two systems have lower coherence at high rates, and the calculation of temperature is very sensitive to small errors in the pressure measurements.

This new measurement of temperature is valuable as a check on the temperature sensors because miscalibration or changes in the sensors will appear as a discrepancy in comparison to this measurement. However, temperature measurement by LAMS also has a very useful potential application in clouds, where backscatter from the cloud particles makes the LAMS signal very strong and where this measurement should continue to be valid. Measurement of temperature in cloud has been challenging because immersion sensors can become wet and, in the dynamically heated airflow, experience wet-bulb cooling to a variable extent dependent on the wetting (e.g. Heymsfield et al., 1979; Wang and Geerts, 2009). If the measurement of temperature available from LAMS remains valid in cloud, it can provide important information on the buoyancy of clouds and would support studies of entrainment via mixing-diagram analysis of the type undertaken by Paluch (1979) or Betts (1983), which can be compromised when using conventional temperature sensors.

Figure 9 illustrates the capability of the LAMS to measure temperature in cirrus clouds. These measurements were made during a descent through a cirrus layer, where the backscattered signal was dominated by the ice crystals that were present in concentrations varying from about $0.1 \mathrm{~L}^{-1}$ to more than $100 \mathrm{~L}^{-1}$. This demonstrates that the LAMS is able to continue to operate in such conditions and that it continues to provide a useful temperature independent of the immersion temperature probes.
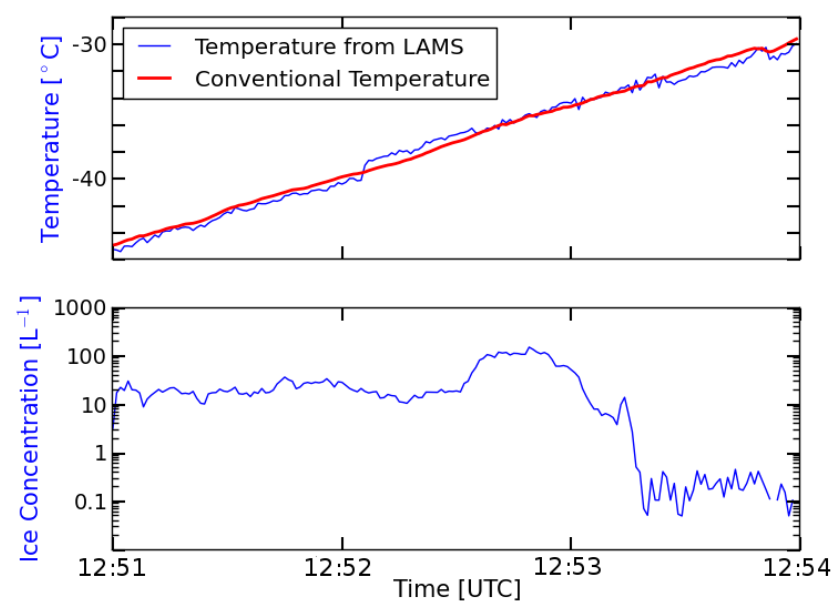

Figure 9. Top panel: temperature determined from LAMS measurements of airspeed using Eq. (24) compared to the temperature measured by a conventional immersion temperature sensor during a descent through a cirrus cloud layer. Bottom panel: the measured ice concentration from a two-dimensional cloud (2-DC) imaging probe.

At this time, it is less certain how the system will perform in water clouds because almost all water clouds encountered with the LAMS have been supercooled and heating of the window was not adequate to prevent accumulation of ice on the window. An example of measurements in a water cloud is shown in Fig. 10. The gap in measurements at about 22:13:15 UTC was caused by loss of signal as a result of icing on the window, but even before that the measured temperature from LAMS was erratic and often systematically about $1{ }^{\circ} \mathrm{C}$ too low. More heating or data from warmer clouds will be needed to test the potential for measurements in water clouds. It is not yet clear that this will be a useful measurement because the backscattered return in dense clouds might be dominated by regions closer than the focal point of the system, where airflow distortion could be important. The change in the location of the sample volume of a laser system was recognized by Werner et al. (1984), and the possible error in sensed airspeed was discussed by Keeler et al. (1987), who recommended modified processing techniques selecting the peak rather than the mean in the Doppler-shifted wavelength spectrum, as used here, for measurements in clouds. Indeed, too low a measurement of airspeed would cause the deduced temperature to be too low, as is the trend in this figure. The small extinction lengths shown in Fig. 10, from 10 to $20 \mathrm{~m}$ in the more dense parts of this cloud, support this explanation. However, the regions with erroneous temperature do not correspond to those with short extinction length as consistently as would be expected if this is the cause of the error in temperature. The performance in water clouds therefore is not yet understood and will need further investigation and additional measurements. 


\section{$7 \quad$ Summary and conclusions}

A new laser air-motion sensor, capable of measuring airspeed via the Doppler shift in a laser beam focused about 15 to $30 \mathrm{~m}$ ahead of the aircraft, has been used to determine corrections to be applied to the wind component along the axis of the aircraft. With these corrections, the standard uncertainty in this component of the wind has been reduced to less than $0.1 \mathrm{~m} \mathrm{~s}^{-1}$. Fits to the corrections deduced from this system, as functions of the measurements of ambient and dynamic pressure as well as angle of attack, support this limit on uncertainty even when the LAMS system is not available. Because the basis for the measurement is the Doppler shift in the frequency of backscattered light, the measurement is not dependent on calibration, and because the measurement is made well ahead of the aircraft, it is unaffected by flow distortion around the aircraft.

Once an accurate measurement of airspeed is available, the expected pressure excess above ambient pressure produced by that airflow at the inlet of a pitot tube can be calculated. The pressure at flight level can then be determined with low uncertainty by subtracting that excess pressure from the measured total pressure at the pitot tube. The estimated uncertainty in that measurement is less than $0.3 \mathrm{hPa}$, and the precision (relevant to pressure mapping while the aircraft remains in steady flight conditions) is about $0.1 \mathrm{hPa}$. Calibration to this level of precision enables improved measurement of mesoscale pressure fields in the atmosphere, following the methods developed by Parish et al. (2007) and Parish and Leon (2013) based on GPS technology and by earlier authors including Brown et al. (1981), Shapiro and Kennedy (1981) and LeMone and Tarleton (1986) on the basis of other measurements of geometric altitude.

With accurate measurement of pressure, combined with excellent measurements of geometric altitude from modern GPS, it is possible to deduce constraints on the temperature measurement from integrations of the hydrostatic equation during climbs and descents. For the GV, a data set consisting of 122 extended climbs and descents, typically over more than $8 \mathrm{~km}$, was used to determine that the measured temperature was within about $0.3^{\circ} \mathrm{C}$ of the values required to minimize differences between calculated and true altitude changes. The correction required was a function of temperature but typically was $+0.3 \pm 0.3^{\circ} \mathrm{C}$. This correction included all effects entering the measurement of ambient temperature at flight level, including corrections dependent on the recovery factor of the temperature probes, which are a significant source of uncertainty because of the large (often $25^{\circ} \mathrm{C}$ ) corrections required for dynamic heating at $\mathrm{GV}$ flight speeds.

Finally, it was shown that the LAMS, combined with parametrized fits to correction factors for the measured dynamic and ambient pressure, can provide a measurement of temperature that is independent of any other temperature sensor. That measurement continues to be valid in all-ice clouds,
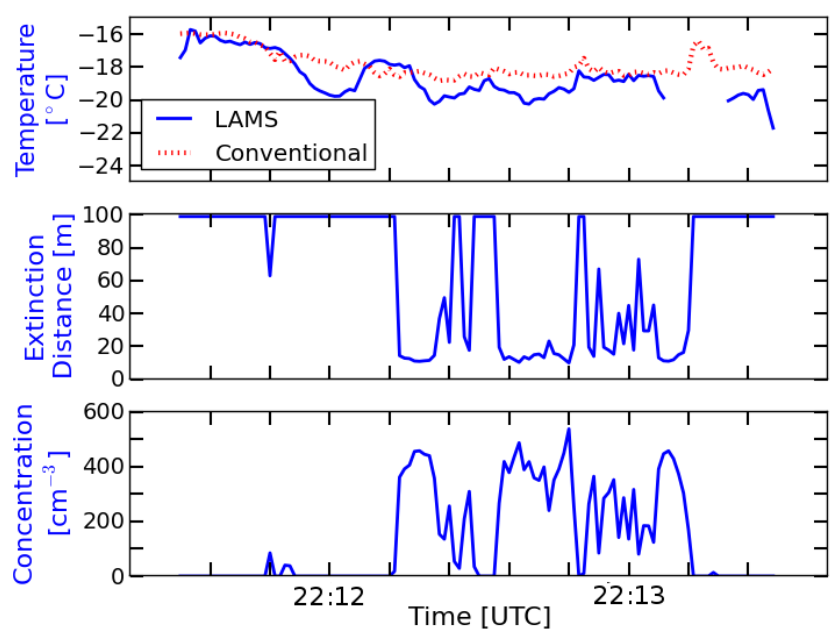

Figure 10. Top panel: temperature determined by the LAMS during a C-130 cloud pass on 15 November 2011. The temperature measured by a conventional temperature probe is also shown. Middle panel: extinction length or distance corresponding to unity optical depth, determined from the measured droplet size distribution. Bottom panel: cloud droplet concentration measured by a cloud droplet probe.

but the limited measurements available in water clouds appear less satisfactory. The latter problem is not understood, but is worth further investigation because most immersion sensors are affected by cloud water and produce erroneously low values in water clouds.

A three-dimensional version of the LAMS is now under development and will be ready for flight testing soon. That will extend the improvements available from LAMS to all three components of the measured wind.

Acknowledgements. The instrument development and data collection were supported by the NCAR Earth Observing Laboratory. Data used in this study were collected during field campaigns led by S. Wofsy (HIPPO), C. Davis (PREDICT) and J. Stith (IDEAS), during which the Research Aviation Facility pilots, mechanics, technicians, and software engineers operated the Gulfstream GV and Lockheed C-130 research aircraft. The authors also thank Jorgen Jensen and Jeff Stith for comments and advice on the manuscript. D. Khelif and two anonymous reviewers provided exceptionally helpful reviews that identified errors and led to significant improvement in the manuscript. The National Center for Atmospheric Research is sponsored by the National Science Foundation.

Edited by: S. Malinowski 


\section{References}

Balachandran, P.: Fundamentals of Compressible Fluid Dynamics, Prentice-Hall of India Pvt-Ltd, available at: http: //books.google.com/books?id=KEzdXmXgaHkC (last access: 21 September 2014), 2006.

Bellamy, J. C.: The use of pressure altitude and altimeter corrections in meteorology, J. Meteorol., 2, 1-79, doi:10.1175/15200469(1945)002<0001:TUOPAA>2.0.CO;2, 1945.

Betts, A. K.: Thermodynamics of mixed stratocumulus layers - saturation point budgets, J. Atmos. Sci., 40, 2655-2670, doi:10.1175/1520-0469(1983)040<2655:TOMSLS>2.0.CO;2, 1983.

Brown, E. N.: Position Error Calibration of a Pressure Survey Aircraft Using a Trailing Cone, NCAR technical note NCAR/TN-313+STR, Atmospheric Technology Division, NCAR, Boulder, CO, USA, available at: http://nldr.library.ucar. edu/repository/collections/TECH-NOTE-000-000-000-579 (last access: 21 September 2014), 1988.

Brown, E. N., Shapiro, M. A., Kennedy, P. J., and Friehe, C. A.: The application of airborne radar altimetry to the measurement of height and slope of isobaric surfaces, J. Appl. Meteorol., 20, 1070-1075, doi:10.1175/15200450(1981)020<1070:TAOARA>2.0.CO;2, 1981.

Brown, E. N., Friehe, C. A., and Lenschow, D. H.: The use of pressure-fluctuations on the nose of an aircraft for measuring air motion, J. Clim. Appl. Meteorol., 22, 171-180, doi:10.1175/1520-0450(1983)022<0171:TUOPFO>2.0.CO;2, 1983.

Cho, A., Kim, J., Lee, S., and Kee, C.: Wind estimation and airspeed calibration using a UAV with a single-antenna GPS receiver and pitot tube, IEEE T. Aero. Elec. Sys., 47, 109-117, doi:10.1109/TAES.2011.5705663, 2011.

Foster, J. and Cunningham, K.: A GPS-based pitot-static calibration method using global output error optimization, Aerospace Sciences Meetings, American Institute of Aeronautics and Astronautics, doi:10.2514/6.2010-1350, 2010.

Gracey, W.: Measurement of Aircraft Speed and Altitude, NASA Reference Publication 1046, NASA Langley Research Center, available at: http://www.dtic.mil/dtic/tr/fulltext/u2/a280006.pdf (last access: 21 September 2014), 1980.

Gracey, W., Letko, W., and Russell, W. R.: Wind Tunnel Investigation of a Number of Total-Pressure Tubes at High Angles of Attack, Subsonic Speeds, no. 2331 in NACA Technical Note, National Advisory Committee for Aeronautics, 1951.

Haering Jr., E. A.: Airdata Measurement and Calibration, NASA Technical Memorandum 104315, NASA Dryden Flight Research Center, available at: http://ntrs.nasa.gov/search.jsp?R= 19990063780 (last access 21 September 2014), 1995.

Heymsfield, A. J., Dye, J. E., and Biter, C. J.: Overestimates of entrainment from wetting of aircraft temperature sensors in cloud, J. Appl. Meteorol., 18, 92-95, doi:10.1175/15200450(1979)018<0092:OOEFWO>2.0.CO;2, 1979.

Ikhtiari, P. A. and Marth, V. G.: Trailing cone static pressure measurement device, J. Aircraft, 1, 93-94, doi:10.2514/3.43563, 1964.

Keeler, R. J., Serafin, R. J., Schwiesow, R. L., Lenschow, D. H., Vaughan, J. M., and Woodfield, A.: An airborne laser air motion sensing system, Part I: Concept and preliminary experi- ment, J. Atmos. Ocean. Tech., 4, 113-127, doi:10.1175/15200426(1987)004<0113:AALAMS>2.0.CO;2, 1987.

Khelif, D., Burns, S. P., and Friehe, C. A.: Improved wind measurements on research aircraft, J. Atmos. Ocean. Tech., 16, 860-875, doi:10.1175/1520-0426(1999)016<0860:IWMORA>2.0.CO;2, 1999.

Kristensen, L. and Lenschow, D. H.: An airborne laser air motion sensing system, Part II: Design criteria and measurement possibilities, J. Atmos. Ocean. Tech., 4, 128-138, doi:10.1175/15200426(1987)004<0128:AALAMS>2.0.CO;2, 1987.

LeMone, M. A. and Tarleton, L. F.: The use of inertial altitude in the determination of the convective-scale pressure field over land, J. Atmos. Ocean. Tech., 3, 650-661, doi:10.1175/15200426(1986)003<0650:TUOIAI>2.0.CO;2, 1986.

Lenschow, D. H.: The measurement of air velocity and temperature using the NCAR Buffalo Aircraft Measuring System, Tech. rep., available at: http://nldr.library.ucar.edu/ repository/collections/TECH-NOTE-000-000-000-064 (last access: 21 September 2014), 1972.

Martos, B., Kiszely, P., and Foster, J.: Flight test results of a GPSbased pitot-static calibration method using output-error optimization for a light twin-engine airplane, in: Guidance, Navigation, and Control and Co-located Conferences, American Institute of Aeronautics and Astronautics, doi:10.2514/6.2011-6669, 2011.

Mayor, S. D., Lenschow, D. H., Schwiesow, R. L., Mann, J., Frush, C. L., and Simon, M. K.: Validation of NCAR 10.6- $\mu \mathrm{m} \quad \mathrm{CO}_{2}$ Doppler lidar radial velocity measurements and comparison with a $915-\mathrm{MHz}$ profiler, J. Atmos. Ocean. Tech., 14, 1110-1126, doi:10.1175/15200426(1997)014<1110:VONMCD>2.0.CO;2, 1997.

Nelder, J. A. and Mead, R.: A simplex-method for function minimization, Comput. J., 7, 308-313, 1965.

Paluch, I. R.: Entrainment mechanism in Colorado cumuli, J. Atmos. Sci., 36, 2467-2478, doi:10.1175/15200469(1979)036<2467:TEMICC>2.0.CO;2, 1979.

Parish, T. R. and Leon, D. C.: Measurement of cloud perturbation pressures using an instrumented aircraft, J. Atmos. Ocean. Tech., 30, 215-229, doi:10.1175/JTECH-D-12-00011.1, 2013.

Parish, T. R., Burkhart, M. D., and Rodi, A. R.: Determination of the horizontal pressure gradient force using global positioning system on board an instrumented aircraft, J. Atmos. Ocean. Tech., 24, 521-528, doi:10.1175/JTECH1986.1, 2007.

$\mathrm{R}$ Core Team: R: a language and environment for statistical computing, R Foundation for Statistical Computing, Vienna, Austria, available at: http://www.R-project.org (last access: 21 September 2014), 2013.

Rodi, A. R. and Leon, D. C.: Correction of static pressure on a research aircraft in accelerated flight using differential pressure measurements, Atmos. Meas. Tech., 5, 2569-2579, doi:10.5194/amt-5-2569-2012, 2012.

Shapiro, M. A. and Kennedy, P. J.: Research aircraft measurements of jet-stream geostrophic and ageostrophic winds, J. Atmos. Sci., 38, 2642-2652, doi:10.1175/15200469(1981)038<2642:RAMOJS>2.0.CO;2, 1981.

Sonnenschein, C. M. and Horrigan, F. A.: Signal-to-noise relationships for coaxial systems that heterodyne backscatter from the atmosphere, Appl. Optics, 10, 1600-1604, doi:10.1364/AO.10.001600, 1971. 
Spuler, S. M., Richter, D., Spowart, M. P., and Rieken, K.: Optical fiber-based laser remote sensor for airborne measurement of wind velocity and turbulence, Appl. Optics, 50, 842-851, doi:10.1364/AO.50.000842, 2011.

Stickney, T. M., Shedlov, M. W., and Thompson, D. I.: Goodrich Total Temperature Sensors, Technical Report 5755, Revision C, Rosemount Aerospace Inc., available at: http://www.faam.ac.uk/index.php/component/docman/doc_ download/47-rosemount-report-5755 (last access 21 September 2014), 1994.

Tropez, C., Yarin, A. L., and Foss, J. F. (Eds.): Springer Handbook of Experimental Fluid Mechanics, Springer, Berlin Heidelberg, doi:10.1007/978-3-540-30299-5, 2007.
Wang, Y. and Geerts, B.: Estimating the evaporative cooling bias of an airborne reverse flow thermometer, J. Atmos. Ocean. Tech., 26, 3-21, doi:10.1175/2008JTECHA1127.1, 2009.

Werner, C., Köpp, F., and Schwiesow, R. L.: Influence of clouds and fog on LDA wind measurements, Appl. Optics, 23, 2482-2484, doi:10.1364/AO.23.002482, 1984.

Wofsy, S. C., Daube, B. C., Jimenez, R., and the HIPPO Science Team and Cooperating Modellers and Satellite Teams: HIAPER Pole-to-Pole Observations (HIPPO): fine-grained, globalscale measurements of climatically important atmospheric gases and aerosols, Philos. T. Roy. Soc. A, 369, 2073-2086, doi:10.1098/rsta.2010.0313, 2011. 